\title{
Görme Engelli Üniversite Öğrencilerinde Zaman Yönetimi Eğitiminin Aktivite Performansına Etkisi
}

The Effect of Time Management Education on Activity Performance of the Visually Impaired University Students

İbrahim Yavuz TATLI ${ }^{\mathbf{1}}$, Gamze EKIC $\mathbf{I}^{\mathbf{2}}$
${ }_{1}$ Uzm. Erg., Sağlık Bilimleri Üniversitesi, Konya Eğitim ve Araştırma Hastanesi, Konya
${ }^{2}$ Prof. Dr., Hacettepe Üniversitesi Sağlık Bilimleri Fakültesi Ergoterapi Bölümü, Ankara

öz

Amaç: Bu çalışma Hacettepe Üniversitesi'nde öğrenim görmekte olan ve gönüllü olarak çalışmamıza katılan bireylere verilen zaman yönetimi eğitiminin öğrencilerin zaman yönetimi becerilerine, aktivite performans ve memnuniyeti düzeyleri üzerine olan etkilerini incelemektir. Gereç ve Yöntem: Bu çalışmaya, dâhil edilme kriterlerine uygun olduğu görülen 10 total görme engelli öğrenci dâhil edildi. Bireylerin cinsiyet, yaş, eğitim gibi bilgileri kaydedildi. Bireylerin öncelikli aktiviteleri ve bu aktivitelerdeki performans, memnuniyet seviyeleri Kanada Aktivite Performans Ölçümü ile zaman yönetimi becerileri ise Zaman Yönetimi Envanteri ile değerlendirildi. Değerlendirme sonrasında 5 hafta süren bir eğitim planı içerisine alındı. Bireylere bu süre zarfında zaman yönetimi eğitimi ergoterapi perspektifi ile uygulandı. Eğitim sonrasında aynı değerlendirmeler ikinci kez uygulandı ve eğitim öncesi durumla karşılaştııılı. Sonuçlar: Bireylerin zaman yönetimi becerileri $\left(p=0,037^{*}\right)$, aktivite performansı $\left(p=0,022^{*}\right)$ ve memnuniyetlerinde $\left(p=0,01^{*}\right)$ eğitim ile beraber istatistiksel açıdan anlamlı artış olduğu görüldü. Tartışma: Bireylerin farklı aktivitelerdeki performansları değişkenlik gösterebilmektedir. Bireylerin genel anlamda gün içinde gerçekleştirdiği aktivitelerin zamansal ilişkisi önemlidir. Bireylerin günlük aktivitelerinin temporal boyutu fiziksel ve sosyal çevrenin etkilerinin de eklenerek değerlendirilmesi faydalı olacaktır.

Anahtar Kelimeler: Görme engelli bireyler; İnsani aktiviteler; Zamanı yönetme

ABSTRACT

Purpose: Purpose: The study was planned to investigate the effects of time management training on time management skills, occupational performance and satisfaction levels of students who attended this study voluntarily. Material and Methods: This study included 10 totally blind students who were found to meet the inclusion criteria. Information such as gender, age and education was recorded. Individuals' prior activities, performance, and satisfaction in these activities were assessed with Canadian Occupational Performance Measure and time management skills with Time Management Inventory. After the evaluation, a training plan for 5 weeks was planned. During this time, the individuals were given time management training with an occupational therapy perspective. After the training, a second evaluation was done with the same assessments tools and the results were compared with the pre-training situation. Results: Statistically, individuals' time management skills $\left(p=0.037^{*}\right)$, activity performance $\left(p=0.022^{*}\right)$ and satisfaction $\left(p=0.01^{*}\right)$ increased significantly with training. Discussion: Individuals' activity performances in different activities can vary. The temporal relationship of the activities performed by individuals in the general sense during the day is important. It will be useful to evaluate the temporal dimension of daily activities of individuals by adding the effects of physical and social circulation.

Key Words: : Visually impaired people; Human activities; Time management 
Türkiye Özürlüler Araştırması'na göre görme özülüler, nüfusun \%0,6'sını oluşturmaktadır. Aynı çalışmaya göre az gören bireyler, görme engellilerin yaklaşık \% 40'ını oluşturmakta ve az görenlerin ülkemizdeki sayısının ise yaklaşık 165 bin olduğu bilinmektedir (Başbakanlık Özürlüler İdaresi Başkanlığı, 2002). Yüksek Öğretim Kurulu istatistiklerine göre ise 2016-2017 eğitim öğretim yılında üniversitelerde 1193 görme engelli öğrenci öğrenim görmüştür (Yüksek Öğretim Kurulu, 2017). Bu verilere göre ülkemizde yaşayan ve üniversite eğitimi alan görme engelli bireylerin sayısı azımsanacak seviyede değildir. Bu büyük topluluğun, sağlıklı bireylere kıyasla rollerini incelemek günlük yaşamda zaman yönetimine duydukları intiyaç açısından faydalı olabilir.

Sağlıklı bir öğrencinin gün içerisinde günlük yaşamda, akademik ve sosyal alanlarda birçok aktiviteyi yerine getirmesi beklenir. Bunları yaparken her biri için gününü planlaması ve uygun miktarda zaman ayırması gereklidir (Sabuncuoğlu ve Tüz, 2001). Sağlıklı bireylere göre görme kaybı olan bireyler, rollerini ve ilişkili aktivitelerini yerine getirirken daha fazla sorunla karşılaşırlar (Chia, Mitchell, Rochtchina ve ark, 2003). Bu sorunlar, görme engelli bireyleri sosyal ve emosyonel açıdan olumsuz etkilemektedir (Chia ve ark, 2003). Görme kaybı günlük yaşamda, sosyal katııımda ve bağımsız hareket açısından problemlere sebep olmaktadır (Lamoureux, Hassell ve Keeffe, 2004; West, Rubin, Broman ve ark, 2002; Weih, Hassell ve Keeffe, 2002).

Görme engelli öğrencilerin sıradan görme engelli bireylerden farklı olarak öğrenci rolü de bulunmaktadır. Bu role sahip bireylerin günlük hayatta bağımsızlıklarını hedef alan ve 9 alanı içeren bir çekirdek eğitim programı (expanded core curriculum) bulunmaktadır (Sapp ve Hatlen, 2010). Bu program, bağımsız hareket, yardımcı teknoloji, kompansatuar teknikler gibi, aktivitelerde farklı ekipman ve yöntemler ile bağımsızlığı sağlamakla beraber dünya genelinde bazı ekipmanların azlığı göze çarpmaktadır. Dünyada yayımlanan kitapların \%95'inin Braille ile yazılmadığı, büyük harf baskılı ve sesli kaynaklar gibi görme engellilerin okuyabileceği, erişilebilir formatlarda olmadığı göz önünde bulundurulduğunda, görme engellilerin özellikle akademik aktivitelerde başarılı performans sağlaması oldukça zordur (Brazier, 2007). Ülkemizde yapılan araştırmalarda ise Türkiye genelindeki üniversiteler kütüphanelerinin, dijital koleksiyonların ve yazılı kaynakların görme engelli öğrencilerin intiyaçlarını karşılamada yetersiz olduğu belirtilmiştir (Aydın, 2011; Bakırcı, 2011). Ancak, akademik aktiviteler de dâhil olmak üzere görme engelli bireylerin sorun yaşadığı aktivitelerin onlar için önemi birbirlerine göre değişiklik gösterse de yeryüzünde gerçekleştirilen her aktivitede 'zaman kavramı' ortaktır (Sabuncuoğlu ve ark, 2001).

Zaman, herkesin eşit olarak sahip olduğu ve hiç kimse tarafından durdurulması mümkün olmayan eşsiz bir kaynaktır (Fidan, 2011). Bir günün 24 saat olduğunu düşünecek olursak, bu süre her ne kadar herkes için aynı olsa da tüm bireyler bu süreyi farklı aktivitelerle doldurabilir. Zamandan bir kaynak olarak bahsetsek de diğer kaynaklara nazaran depolanması, çoğaltılması veya yerine başka bir kaynağın koyulması mümkün değildir (Fidan, 2011). Bu nedenle, zaman yönetimi zamanı doğru kullanmak açısından hayati önem taşır (Covey, Merrill ve Merrill, 1995).

Zaman yönetimi, yunanca kronolojik zaman anlamına gelen 'Kronos'la ilgilidir. Kronos, doğrusal ve ardışık niteliktedir (Sabuncuoğlu ve ark, 2001). Zaman yönetiminde temel hedef, bireyin kendisini ve işlerini yaşanan zaman süresi içerisinde istenen seviyede planlamasıdır (Türkel, 1999). Bu planlama aslında bir öz yönetimdir. Yaşanılan olayların kontrolünü ele almak ve bireyin kendisini yönlendirerek olayları temporal açıdan yönetmesidir (Güçlü, 2001). Temel düşünce ise gün içerisindeki zaman dilimlerinin daha iyi planlanarak verimli kullanılmasıdır (Koch, 1999).

Zaman yönetimi eğitimi kapsamında, 'düzenli yaşama yaklaşım, savaşçı yaklaşım, ABC yaklaşımı, hedef belirleme yaklaşımı, sihirli araç yaklaşımı' gibi yöntemler kullanılır (Sabuncuoğlu ve ark, 2001). Bu müdahalelerin uygulanmasındaki temel amaç, zamanı doğru kullanarak, aktivite performansını iyileştirmektir (Uğur, 2000). Bu nedenle, zamanın aktivite içerisindeki kullanımı oldukça önemlidir (Uğur, 2000).

Ergoterapi müdahalelerinin odak noktası aktivitelere katıımın sağlanmasıdır. Aynı zamanda, performansın hem sübjektif (emosyonel ve psikolojik), hem de objektif (fiziksel olarak gözlemlenebilen) yönleri ile ilgilenir (Roley, DeLany, Barrows ve ark, 2008). Aktivite performansı, kişi, oküpasyon ve çevrenin dinamik etkileşimi arasında seçilen aktivitenin yerine getirilmesindeki başarıyı gösterir (American Occupational Therapy Association, 2014). Performansın önemli bir parçası olan kişinin etrafında şekillenen 4 temel bağlam vardır ve bunlardan biri zaman ve onun şekillendirilmesidir (Larson ve Zemke, 2003). Bu, kişinin aktivitelere katıımını etkileyen önemli bir faktördür. Aktivitelerin, günlerin ve haftaların şekillendirilmesi, aktivitelerin bir denge içerisinde bulundurulması, aktivite performansındaki gibi 
(Christiansen ve Baum, 1997) yaşam kalitesi, sağlık ve iyilik hali için önemli bir yere sahiptir (Erlandsson \& Eklund, 2001; Persson, Erlandsson, Eklund, \& Iwarsson, 2001).

Görme engelli öğrencilere verilen zaman yönetimi eğitiminin, zaman yönetimi becerilerine veya aktivite performans düzeyine etkisini incelemek aktivitenin temporal boyutuna farklı bir bakış açısı getirebilir düşüncesindeyiz. Bu çalışmadaki amaç, görme engelli üniversite öğrencilerine verilen zaman yönetimi eğitiminin öğrencilerin zaman yönetimi becerilerine, aktivite performansları ve memnuniyet düzeyleri üzerine olan etkisini incelemektir.

\section{GEREÇ VE YÖNTEM}

Bireyler

Hacettepe Üniversitesi'nde öğrenim gören, total görme kaybı olan 10 öğrencinin dâhil edildiği bu çalışma, Ocak 2015 - Ocak 2017 yılları arasında tamamlanmıştır. Bu çalışma için dâhil edilme kriterleri total görme kaybı olmak ve üniversite öğrencisi olmaktır. Dâhil edilmeme kriteri ise görme engeli dışında bilinen bir sağlık sorununun bulunmasıdır. Yukarıdaki kriterlere göre 57 total görme engelli öğrenci ile görüşülmüştür. Bireylerin 23'ü başka sağlık problemine sahip olduklarından, 14'ü katılmayı reddettiğinden çalışma dışı kalmıştır. Bireylerin 6'sı kişisel programları yoğunlaştığı, 4'ü ise görev aldıkları milli spor müsabakaları için şehir dışına çıkmak durumunda kaldığından eğitimi tamamlayamamıştır.

Dâhil edilme kriterlerine uygun bulunan bireyler ile yüz yüze görüşme gerçekleştirilmiş olup, çalışmanın amacı ve yöntemi konusunda gerekli bilgiler verilmiştir. Tüm bireylerden Helsinki deklarasyonuna uygun olarak sözlü onam alınmıştır.

Yöntem

Değerlendirmeler ve zaman yönetimi eğitimi, öğrencilerin Hacettepe Üniversitesi, Beytepe Yerleşkesi'ndeki bölümlerine gidilerek uygulanmıştır. Eğitim öncesinde bireylerin cinsiyet, yaş, bölüm bilgileri kaydedilmiştir. Aynı zamanda, sigara kullanımları, uyku süreleri ve yardımcı cihaz kullanımları da sorgulanmıştır. Buna ek olarak, öğrencilerin zaman yönetimi becerileri 'Zaman Yönetimi Envanteri' ile aktivite performans ve memnuniyet düzeyleri ise 'Kanada Aktivite Performans Ölçümü' kullanılarak eğitim öncesi ve sonrası olmak üzere iki kez incelenmiştir.

Zaman Yönetimi Envanteri (ZYE): Zaman
Yönetimi Envanteri, Britton ve Tesser tarafından 1991 yılında geliştirilmiştir (Britton ve Tesser, 1991). Envanterin Türkçe versiyon çalışması 2002 yılında Alay ve Koçak tarafından yapılmıştır (Alay ve Koçak, 2002). Zaman Yönetimi Envanteri başlıklar halinde uygulanan bir ankettir.

Envanter, Zaman Planlaması (16 madde), Zaman Tutumları ( 7 madde) ve Zaman Harcattırıcıları (4 madde) olmak üzere 3 alt başlığa sahip olup toplam 27 maddeden oluşur. Zaman Planlaması uzun ve kısa süreli (bir günlük veya haftalık) planlamayı, Zaman Tutumları, bireyin zaman yönetimini sağlamaya yönelik girişimleri, Zaman Harcattırıcılar ise zamanı kötüye kullanıma neden olacak aktivitelere ayrılan vakti sorgulamaya yönelik maddeleri içermektedir. Her madde 5 puan üzerinden puanlanmaktadır (Her zaman, sık sık, bazen, nadiren, hiç), puanlama 1 ile 5 arasında yapılmaktadır. $\mathrm{Bu}$ üç bölümden alınan puanların toplamı ZYE toplam skorunu oluşturmaktadır. Bu anketten alınabilecek minimum puan 27; maksimum puan ise 135'tir (Alay ve ark, 2002).

Kanada Aktivite Performans Ölçümü (KAPÖ): Bireylerin aktivite performansı ve memnuniyet düzeylerini değerlendirebilmek için KAPÖ kullanılmıştır. KAPÖ, aktivite performansındaki problemleri tanımlamaya ve bireylerin bu aktivitelerdeki performanslarından ne ölçüde memnun olduğunu anlamamıza yardımcı olan yarı yapılandırılmış bir ölçümdür (Arbesman, Lieberman ve Thomas, 2011). Ölçeğin Türkçe geçerlilik ve güvenilirlik çalışması 2017 yılında gerçekleştirilmiştir (Torpil ve Ekici, 2017).

Değerlendirmede bireylerden kendine bakım, serbest zaman, iş ve üretkenlik aktiviteleri alanlarında yaşadıkları problemleri belirlemesi istenir. Sonrasında belirledikleri her aktiviteye likert skalasına göre 0-10 arasında bir önem değeri vermesi istenir (0-Hiç önemli değil, 10-çok önemli). Devam eden aşamada kendileri için en önemli en az 1, en fazla 5 aktiviteyi seçmeleri ve bu aktivitelerin her biri için yine likert skalasına göre 010 arasında performans ve memnuniyet puanı vermeleri istenir. Elde edilen performans ve memnuniyet puanları toplanarak bireyin belirttiği aktivite sayısına bölünür bununla toplam performans ve memnuniyet puanları elde edilir (Law, Bapiste, Carswell ve ark, 1990).

Zaman Yönetimi Eğitimi

Lakein, bireylerin istek ve beklentileri yönünde aktivitelerini önceliklerine göre sıralamasını sağlayan zaman yönetimi modelinin temellerini atmıştır (Lakein, 1973). Macan ve arkadaşları da ilerleyen yıllarda bu modeli yeniden incelemiş ve Lakein'in modelinin rehberliğinde bireylerin zamanlarını daha iyi yönetebilmeleri için üç farklı yaklaşım üzerine 
odaklanmışlardır; a) Zaman yönetiminin mekaniği, b) Organize etmenin özellikleri, c) Öncelikleri ve hedefleri belirleme (Macan, Shahani, Dipboye ve ark, 1990). Eerde'nin 2003 yılında iş ortamındaki personele verdiği 1 aylık zaman yönetimi eğitimi çalışmamızın planlamasında bir örnek olarak kullanılmıştır (Eerde, 2003).

Çalışmamızın eğitim programı bu üç başlığı içermiş, 2 hafta eğitim, 1 hafta planlama ve 2 hafta izleme olmak üzere 5 haftalık bir süreci kapsamıştır. Eğitim haftalarında, bir araştırmacı elektronik kaynaklardan da destek alarak, tüm bireylerin olduğu gruba 45 dakikalık bir eğitim semineri düzenlemiş, her hafta bir sonraki haftaya kadar tekrarlanması için bireylere sesli eğitim notları vermiştir. Planlama haftasında, araştırmacı ve katılımcılar birebir görüşme şeklinde, KAPÖ'ye göre belirlenen aktivitelere yeterli zamanı ayırmak için 2 haftalık kısa dönem hedefleri planlamışlardır. Geriye kalan haftalarda ise bu plana olan uyum izlenmiş, bireylerin sorunlarına yönelik yeni adımlar atılarak hedefler yenilenmiştir. Eğitimin haftalara göre uygulanma düzeni ise şu şekilde gerçekleşmiştir: 1.hafta, bireylere 'Zaman yönetimi mekaniği ve aktivitelerin zamansal boyutu', 2.hafta ise 'Zamanı organize etmenin özellikleri' hakkında eğitimler verilmiştir. 3.hafta, bireylerin KAPÖ'ye göre belirledikleri aktiviteler önceliklerine göre sıralanmış ve 2 haftalık kısa dönem hedefleri belirlenmiştir. 4. ve 5.haftalar izleme haftası olarak düzenlenmiş ve zaman yönetimi bireyin problemli performans alanlarına yeniden planlanmıştır ve 5 . haftanın sonunda ise eğitim tamamlanmıştır.

\section{Istatiksel Analiz}

Verilerin istatiksel analizinde SPSS 21.00 programı kullanılmıştır. Ölçümle belirtilen değişkenler, Ortalama \pm Standart Sapma $(\mathrm{X} \pm \mathrm{SS})$ olarak ifade edilmiş, sayımla belirlenen değişkenler için yüzde (\%) değeri hesaplanmıştır. Çalışmaya katılan bireylerin zaman yönetimi becerileri, aktivite performansları ve açısından eğitim öncesi ve sonrası değerleri Wilcoxon işaretli sıra testi ile incelenmiştir. KAPÖ' deki aktivite performansı ve memnuniyet puanını bulmak için bireylerin toplam aktivite performansı (aktivite performansları toplamı/aktivite sayısı) ve toplam memnuniyet puanları (aktivite memnuiyetleri toplam laktivite sayısı) hesaplanmış ve grup ortalamasına ulaşılmıştır (Torpil, 2017; Gilbertson ve Langhorne, 2000; Carpenter, Baker ve Tyldesley, B. (2001).

\section{SONUÇLAR}

Katılımcıların 6'sı (\%60) kadın, 4'ü (\%40) erkektir ve yaş ortalamaları 20,7 $\pm 3,25$ yıldır. Bireylerin 9'u (\%90) Eğitim Bilimleri Fakültesi'nde, 1'i (\%10) ise Spor Bilimleri Fakültesi'nde öğrenim görmektedir. Katılımcılar içerisinde sigara kullanan bulunmamaktadır. Bireylerin uyku sürelerinin ortalaması 6,6 $\pm 2,3$ saat/gündür. Tüm bireyler yardımcı cihaz olarak baston kullanmaktadır.

Bireylerin KAPÖ' ye göre belirlediği aktivitelerin sayısı, 'Kendine Bakım, Üretkenlik ve Serbest Zaman'dan oluşan performans alanlarına yerleştirilmiştir. Kendine Bakım alanında en fazla 'Toplumda Kendini İdare Etme' aktiviteleri tercih edilmiştir. Bu alanda performans ve memnuniyet artışı ise en fazla 'Kişisel Bakım' aktivitelerinde olmuştur. Üretkenlik aktivite alanında en fazla 'Okul ve/veya Oyun' aktiviteleri tercih edilmiştir. Bu alanda en fazla performans ve memnuniyet artışı ise 'Ev İşi Yönetimi' aktivitelerinde olmuştur. Serbest Zaman aktivite alanında en fazla 'Sessiz Rekreasyon' aktiviteleri tercih edilmiştir. Bu alanda performans artışı en fazla 'Sessiz Rekreasyon' aktivitelerinde, en fazla memnuniyet artışı ise 'Aktif Rekreasyon' aktivitelerinde olmuştur.

Zaman Yönetimi Envanteri $\left(p=0,037^{*}\right)$ sonuçları, aktivite performansı $\left(p=0,022^{*}\right)$ ve memnuniyetlerinin $\left(p=0,01^{*}\right)$ en düşük/en yüksek değerleri ve ortalama skorları eğitim öncesi ve sonrası olmak üzere karşılaştırılarak Tablo 1'de sunulmuştur. Tüm parametrelerde istatistiksel olarak anlamlı artışlar görülmüştür.

Tablo 1. Bireylerin eğitim öncesi ve sonrası Zaman Yönetimi Envanteri (ZYE) ve Kanada Aktivite Performans Ölçümü (KAPÖ) sonuçlarının karşılaştırılması

\begin{tabular}{ccccccc}
\hline & \multicolumn{7}{c}{$\begin{array}{c}\text { Eğitim Sonrası } \\
\text { En düşük I } \\
\text { En yüksek }\end{array}$} & $\mathbf{X} \pm \mathbf{S S}$ & $\begin{array}{l}\text { En düşük I } \\
\text { En yüksek }\end{array}$ & $\mathbf{X} \pm \mathbf{S S}$ & $\mathbf{z}$ & $\mathbf{p}$ \\
\hline Zaman Yönetimi Envanteri & $67 / 96$ & $84,20 \pm 9,93$ & $73 / 117$ & $97,40 \pm 12,06$ & $-2,556$ & $0,037^{*}$ \\
\hline KAPÖ Performans & $3 / 8$ & $5,71 \pm 1,43$ & $4 / 9$ & $6,41 \pm 1,47$ & $-2,881$ & $0,022^{*}$ \\
\hline Memnuniyet & $3 / 7$ & $5,1 \pm 1,52$ & $4 / 8$ & $6,33 \pm 1,37$ & $-1,991$ & $0,01^{*}$ \\
\hline
\end{tabular}

\section{TARTIŞMA}

Görme engelli öğrencilerde, bireyin zaman yönetimi eğitiminin zaman yönetimi becerileri, aktivite performans ve memnuniyeti düzeyleri üzerine olan etkilerini inceleyen bu çalışmada, eğitimin zaman yönetimi becerilerini geliştirdiği, kendilerine göre 
öncelikli olan aktivelerinde ise performans ve memnuniyet düzeylerini artırdığı bulunmuştur. Bazı aktivite alanlarında hem performans hem de memnuniyette bazı alanlarda ise performans artışından bağımsız sadece memnuniyet seviyelerinde bir artış olduğu görülmüştür.

Aktiviteler, transaksiyonel bir yapıya sahip olup 'vücut yapısı' ve 'zaman' da bu yapının içerisinde yer almaktadır (Cutchin ve Dickie, 2013). Bu çalışmada, görme kaybı yaşayan bireylerin transaksiyonel aktivitelerini zaman yönetimi ile desteklemenin yararlı olduğu görülmüştür.

Nadinloyi ve arkadaşları, zaman yönetimi eğitiminin akademik aktiviteler üzerine olumlu etkiye sahip olduğunu, ayrıca zaman yönetiminin eğitimle geliştirilebileceğini (Nadinloyi ve ark, 2013), başka birçok araştırmacı da zaman yönetimi eğitiminin sağlıklı bireylerin iş performansına ve etkileşim becerilerine olumlu etkisi olduğunu göstermiştir (Nonis ve Sager, 2003; Conte, 1996; Britton ve ark, 1991; Macan ve ark, 1990; Davis, 2000). Çalışmamızda zaman yönetimi eğitimi sonrasında bireylerin zaman yönetimi becerilerinin arttığı aynı şekilde gözlemlenmiştir. Akademik ve mesleki aktivitelerin yanı sıra diğer aktivite alanlarından da seçimde bulunan bireylerin aktivite performansının da eğitim sonrası durumda yüksek olduğu görülmüştür.

Çalışmalar, görme becerisinde meydana gelecek bir kaybın günlük yaşam aktivitelerinin, üretici ve sosyal çevredeki aktivitelerin büyük çoğunluğunu önemli derecede etkilediğini göstermiştir ( Vu, Keeffe, McCarty ve ark, 2005; Lamoureux ve ark, 2004; West ve ark, 2002). Çalışmamızda bireyler, problem yaşadıkları aktivitelere bu alanların tamamından örnekler vermiş ve özellikle kendine bakım ile üretici aktivitelerinde eğitim sonrasında öncesine göre memnuniyet artışı olduğu görülmüştür. Günlük aktivitelerde, plan ve tutum yönünden bir dengenin oluşmuş olması, bu değişimi sağlamış olabilir. Öğrenciler için önemli olduğunu düşündüğümüz okul aktivitelerini incelemek faydalı olabilir.

Alay ve arkadaşları, 361 üniversite öğrencisinde zaman yönetimi ile akademik beceri arasındaki ilişkiyi incelemiştir. Bu çalışmada, zaman yönetimi ile akademik beceriler arasında anlamlı bir ilişki bulunmuştur (Alay ve Koçak, 2003). Başak ve arkadaşları ise hemşirelik yüksekokulunda okuyan 323 öğrenciye ZYE uygulamıştır. Çalışma sonucunda zaman yönetimi becerileri iyi olan öğrencilerin akademik başarılarının yüksek olduğu belirtilmiştir (Başak, Uzun ve Arslan, 2008). Çalışmamızın sonuçlarına göre akademik aktivitelerde eğitim sonrası performans artmış olmamakla birlikte, bu aktivitelerin uzun zaman aralıklarındaki değerlendirmelere (sınavlar, projeler vb.) bağlı olduğu düşünüldüğünde iki değerlendirme arası sürenin uzun olmaması bu alanda yeterli performans artışının olmadığını ifade etmemizi sağlayabilir. Bununla beraber çalışmamızda farklı olarak performanstan duyulan memnuniyetin değerlendirilmesine yer verilmiştir ve okul aktivitelerinde eğitim öncesine göre memnuniyet artışı gözlemlenmiştir. Bunun, bireylerin artan zaman yönetimi becerileri ile performanslarını arttırabilecekleri düşüncesinden kaynaklandığını söyleyebiliriz.

$\mathrm{Bu}$ çalışma bazı limitasyonlara sahiptir. Birincil olarak, bireylerin günlük zaman kullanımlarının değerlendirilmemesi limitasyon olarak görülmüştür. Fiziksel ve sosyal çevredeki destek ve bariyer noktalarının değerlendirilmemesi de çalışmamızın diğer bir limitasyonu olduğu söylenebilir. Bu kapsamda bireylerin günlük aktivitelerinin temporal anlamda değerlendirilmesi ve çevre faktörlerinin de göz önünde bulundurulması gelecekteki çalışmaların sonuçlarını olumlu yönde etkileyebilir. Literatürde görme engelli bireylerin zaman yönetimi becerileri veya aktivite performansı durumları ile ilgili kısıtlı araştırmanın olması da çalışmanın sonuçlarını yorumlamak açısından bir limitasyon olarak görülmüştür.

Yapılan bu çalışma, görme engelli bir öğrencinin gün içerisinde yaşadığı zorluklar nedeniyle gününü planlayarak, zamanını daha etkili kullanmasının aktivite performansında daha başarılı olması konusunda yardımcı olabileceğini bize göstermiştir. Daha iyi bir zaman yönetimi becerisinin aktivitelerdeki memnuniyeti arttıracağı sonucuyla bireylerin daha iyi bir rol performansı gösterebileceğini ve memnuniyetin de bu doğrultuda artacağını ifade edebiliriz.

\section{Kaynaklar}

Alay, S., \& Koçak, S. (2002). Zaman yönetimi anketi: Geçerlik ve güvenirlik. Hacettepe Üniversitesi Eğitim Fakültesi Dergisi, 22(22), 9-13.

Alay, S., \& Koçak, S. (2003). Üniversite Öğrencilerinin Zaman Yönetimleri ile Akademik Başarıları Arasındaki İlişki. Kuram ve Uygulamada Eğitim Yönetimi Dergisi, 9(3), 326-335.

Arbesman, M., Lieberman, D., \& Thomas, V. J. (2011). Methodology for the systematic reviews on occupational therapy for individuals with work-related injuries and illnesses. Am J Occup Ther, 65(1), 10-15.

Amini, D. A., Kannenberg, K., Bodison, S., Chang, P., Colaianni, \& et al. (2014). Occupational therapy practice framework: 
Domain \& process 3rd edition. Am J Occup Ther, 68, S1-S48.

Aydın, A. (2012). Görme Engelli Üniversite Öğrencilerinin Bilgi Erişim Sorunları Üzerine Yapılmış Bir Araştırma. Bilgi Dünyası, 13(1), 93-116.

Bakırcı, R. (2011). Hollanda'da görme engellilere verilmekte olan dijital erişimli bilgi sistemi ve Türkiye'de durum. Türk Kütüphaneciliği, 25(2), 306-311.

Başak, T., Uzun, Ş., \& Arslan, F. (2008). Hemşirelik yüksekokulu öğrencilerinin zaman yönetimi becerileri. TAF Preventive Medicine Bulletin, 7(5), 429-434.

Başbakanlık Özürlüler İdaresi Başkanlığı (BÖIB), (2002). Türkiye Özürlüler Araştırması. Ankara: Devlet İstatistik Enstitüsü Matbaası.

Brazier, H. (2007). The role and activities of the IFLA Libraries for the Blind section. Library Trends, 55(4), 864-878.

Britton, B. K., \& Tesser, A. (1991). Effects of timemanagement practices on college grades. Journal of Educational Psychology, 83(3), 405-410.

Carpenter, L., Baker, G. A., \& Tyldesley, B. (2001). The use of the Canadian Occupational Performance Measure as an outcome of a pain management program. Can $\mathrm{J}$ Occup Ther, 68(1), 16-22.

Chia, E. M., Mitchell, P., Rochtchina, E., Foran, S., \& Wang, J. J. (2003). Unilateral visual impairment and health related quality of life: The Blue Mountains Eye Study. Br J Ophthalmol, 87(4), 392-395.

Christiansen, C., \& Baum, C. M. (Eds.). (1997). Occupational therapy: Enabling function and wellbeing. Thorofare, N.J.: Slack.

Conte, J. M. (1996). Meta-analysis of the relationship between time orientation and work outcomes. Poster session presented at the 104. Convention of the American Psychological Association, Toronto, Canada.

Covey, S. R., Merrill, A. R., \& Merrill, R. R. (1995). First things first. New York: Simon and Schuster.

Dickie, V. A., \& Cutchin, M. P. (2013). Transactional perspectives on occupation: Main points of contribution in this volume. Transactional Perspectives on Occupation (pp. 257-261) Dordrecht: Springer.

Davis, M. A. (2000). Time and the nursing home assistant: Relations among time management, perceived control over time, and work-related outcomes. Poster presented at Academy of Management Toronto, Canada (pp. 365-380).

Eerde, W. V. (2003). Procrastination at work and time management training. J Psychol, 137(5), 421-434.

Erlandsson, L-K., \& Eklund, M. (2001). Describing patterns of daily occupations-A methodological study comparing data from four different methods. Scand $J$ Occup Ther, 8, 31-39.

Fidan, Y. (2011). ÖZEL SEKTÖR VE KAMU YÖNETICILERININ ZAMAN YÖNETIMI DAVRANIŞLARININ KARŞILAŞTIRILMASI. Adıyaman Üniversitesi Sosyal Bilimler Enstitüsü Dergisi, 4(6), 47-74.

Güçlü, N. (2001). Zaman Yönetimi. Kuram ve Uygulamada Eğitim Yönetimi, 25(25), 87-106.

Gilbertson, L., \& Langhorne, P. (2000). Home-based occupational therapy: Stroke patients' satisfaction with occupational performance and service provision. $\mathrm{Br} \mathrm{J}$
Occup Ther 63, 464-468

Koch, R. (1999). 80/20 ilkesi. Daha Azıyla Daha çoğunu Elde Etmenin Sırrı. (Çev.: Kerem Özdemir). İstanbul: Varlık Yayınları, Sayı: 537.

Lakein, A. (1973). How to Get control of Your Time and Your Life. New York, NY: New American Library.

Lamoureux, E.L., Hassell, J.B., \& Keeffe, J.E. (2004). The determinants of participation in activities of daily living in people with impaired vision. Am J Ophthalmol, 137(2), 265270.

Larson, E., \& Zemke, R. (2003). Shaping the temporal patterns of our lives: The social coordination of occupation. J Occup Sci, 10, 80-89.

Law M., Baptiste S., McColl M., Carswell A., Polatajko H., \& Pollock N (1990). The Canadian occupational performance measure: an outcome measure for occupational therapy. Can J Occup Ther, 57(2), 82-7.

Macan, T. H., Shahani, C., Dipboye, R. L., \& Phillips, A. P. (1990). College students' time management: Correlations with academic performance and stress. Journal of Educational Psychology, 82(4), 760-768.

Nadinloyi, K. B., Hajloo, N., Garamaleki, N. S., \& Sadeghi, H. (2013). The study efficacy of time management training on increase academic time management of students. Procedia Soc Behav Sci, 84, 134-138.

Nonis, S. A., \& Sager, J. K. (2003). Coping strategy profiles used by salespeople: Their relationships with personal characteristics and work outcomes. Journal of Personal Selling \& Sales Management, 23(2), 139-150.

Persson, D., Erlandsson, L-K., Eklund, M., \& et al. (2001). Value dimensions, meaning, and complexity in human occupationA tentative structure for analysis. Scand J Occup Ther, 8, 718.

Roley, S. S., DeLany, J. V., Barrows, C. J., Brownrigg, S., Honaker, D., Sava, D. I. et al. (2008). Occupational therapy practice framework: domain \& practice, 2 nd edition. $A m \mathrm{~J}$ Occup Ther, 62(6), 625-683.

Sabuncuoğlu, Z., \& Tüz, M. (2001). Örgütsel Psikoloji, Ezgi Kitabevi, 3. Baskı, Bursa.

Sapp, W., \& Hatlen, P. (2010). The Expanded Core Curriculum: Where We Have Been, Where We Are Going, and How We Can Get There. J Vis Impair Blind, 104(6).

Torpil. (2017). Multipl Skleroz'lu Bireylerde Kanada Aktivite Performans Ölçümü'nün Türkçe Kültürel Adaptasyonu, Geçerlilik ve Güvenilirliği. Yayınlanmamış yüksek lisans tezi, Hacettepe Üniversitesi Sağlık Bilimleri Enstitüsü, Ankara.

Türkel, A. (1999). Globallesen Dünyanın Süper Yöneticilerine. İstanbul: Türkmen Kitapevi.

Uğur, A. (2000). Çalışma Hayatında Zaman Yönetimi. Anahtar Dergisi, 12(143), 18-22.

Vu, H. T. V., Keeffe, J. E., McCarty, C. A., \& Taylor, H. R. (2005). Impact of unilateral and bilateral vision loss on quality of life. Br J Ophthalmol, 89(3), 360-363.

West, S. K., Rubin, G. S., Broman, A. T., Munoz, B., BandeenRoche, K., \& Turano, K. (2002). How does visual impairment affect performance on tasks of everyday life?: The SEE Project. Arch Ophthalmol, 120(6), 774-780.

Weih, L. M., Hassell, J. B., \& Keeffe, J. (2002). Assessment of the impact of vision impairment. Invest Ophthalmol Vis Sci, 43(4), 927-935.

Yüksek Öğretim Kurulu, (2018). Engelli Öğrenci İstatistikleri. İnternet sitesinden 19.02.2018 tarihinde alınmıştır. https://istatistik.yok.gov.tr/ 